OPEN ACCESS

Edited by:

Hans J. De Boeck,

University of Antwerp, Belgium

Reviewed by:

Ivika Ostonen,

University of Tartu, Estonia

Sonja Leitner,

International Livestock Research

Institute, Kenya

*Correspondence:

Ludovica D'Imperio Idi@ign.ku.dk

Specialty section:

This article was submitted to

Functional Plant Ecology,

a section of the journal

Frontiers in Plant Science

Received: 14 May 2018 Accepted: 09 August 2018 Published: 30 August 2018

Citation

D'Imperio L, Arndal MF, Nielsen CS, Elberling B and Schmidt IK (2018)

Fast Responses of Root Dynamics

to Increased Snow Deposition and Summer Air Temperature in an Arctic Wetland.

Front. Plant Sci. 9:1258. doi: 10.3389/fpls.2018.01258

\section{Fast Responses of Root Dynamics to Increased Snow Deposition and Summer Air Temperature in an Arctic Wetland}

\author{
Ludovica D'Imperio $^{1,2 *}$, Marie F. Arndal ${ }^{1,2}$, Cecilie S. Nielsen ${ }^{1,3}$, Bo Elberling ${ }^{1}$ and \\ Inger K. Schmidt ${ }^{2}$ \\ ${ }^{1}$ Center for Permafrost (CENPERM), Department of Geosciences and Natural Resource Management, University \\ of Copenhagen, Copenhagen, Denmark, ${ }^{2}$ Section for Forest, Nature and Biomass, Department of Geosciences and Natural \\ Resource Management, University of Copenhagen, Frederiksberg, Denmark, ${ }^{3}$ Department of Forest Ecology \\ and Management, Swedish University of Agricultural Sciences, Umeå, Sweden
}

In wet tundra ecosystems, covering vast areas of the Arctic, the belowground plant biomass exceeds the aboveground, making root dynamics a crucial component of the nutrient cycling and the carbon (C) budget of the Arctic. In response to the projected climatic scenarios for the Arctic, namely increased temperature and changes in precipitation patterns, root dynamics may be altered leading to significant changes in the net ecosystem $\mathrm{C}$ budget. Here, we quantify the single and combined effects of 1 year of increased winter snow deposition by snow fences and summer warming by opentop chambers (OTCs) on root dynamics in a wetland at Disko Island (West Greenland). Based on ingrowth bags, snow accumulation decreased root productivity by $42 \%$ in the 0-15 cm soil depth compared to ambient conditions. Over the growing season 2014, minirhizotron observations showed that root growth continued until mid-September in all treatments, and it peaked between the end of July and mid-August. During the season, plots exposed to experimental warming showed a significant increase in root number during September (between 39 and 53\%) and a 39\% increase in root length by the beginning of September. In addition, a significant reduction of root diameter (14\%) was observed in plots with increased snow accumulation. Along the soil profile $(0-40 \mathrm{~cm})$ summer warming by OTCs significantly increased the total root length (54\%), root number (41\%) and the root growth in the $20-30 \mathrm{~cm}$ soil depth (71\%). These results indicate a fast response of this ecosystem to changes in air temperature and precipitation. Hence, on a short-term, summer warming may lead to increased root depth and belowground $\mathrm{C}$ allocation, whereas increased winter snow precipitation may reduce root production or favor specific plant species by means of reduced growing season length or increased nutrient cycling. Knowledge on belowground root dynamics is therefore critical to improve the estimation of the $\mathrm{C}$ balance of the Arctic.

Keywords: arctic tundra, minirhizotrons, open top chambers (ОTC), root dynamics, snow fence, warming, wetland 


\section{INTRODUCTION}

Wetlands are widespread in the Arctic and cover about $7 \%$ of its vegetated area (Walker et al., 2005). In these ecosystems, the accumulation of soil organic carbon (SOC) exceeds the rates of decomposition due to the low soil temperature and lack of oxygen during periods of high water-table (Sullivan et al., 2008). Consequently, wetlands represent a vast reservoir of C (Hugelius et al., 2014). In a warmer and in particular drier future climate, this $\mathrm{C}$ stock may become available for biological decomposition and arctic wetlands consequently play a central role in balancing the uptake and release of carbon dioxide $\left(\mathrm{CO}_{2}\right)$ and methane $\left(\mathrm{CH}_{4}\right)$ on a global level (Swindles et al., 2015). Links between plant communities, soil parameters and processes represent an important control over the C cycle (Wookey et al., 2009). In the Arctic, the belowground plant biomass exceeds its aboveground counterpart (Mokany et al., 2006; Iversen et al., 2015; Wang et al., 2016a) and therefore represents an important component of soil nutrient cycling and net ecosystem $\mathrm{C}$ budget (Iversen et al., 2015). As concluded by Blume-Werry et al. (2016) neither the knowledge from non-Arctic ecosystems, nor projections of aboveground to belowground production, reflect seasonal dynamics of root growth in arctic plant communities and limited data is available on root phenology in this region (Radville et al., 2016).

According to the projected climatic scenarios, air temperatures across the Arctic are expected to increase more than the global average, in particular during winter (McGuire et al., 2012). At high latitudes, increased air winter temperature is expected to trigger an increase in precipitation as snow fall, though with large regional to local variations (Christensen et al., 2013). On the one hand, a thicker snow cover during winter will thermally insulate the soil preventing large fluctuations in soil surface temperature (Morgner et al., 2010) and will enhance nitrogen $(\mathrm{N})$ mineralization rates taking place during the shoulder and cold seasons (Giblin et al., 1991; Schmidt et al., 1999; Schimel et al., 2004). This has been shown to increase the $\mathrm{N}$-availability in the growing season, the $\mathrm{N}$-content of plant leaves and summer season photosynthesis rates (Cooper, 2014; Semenchuk et al., 2015). On the other hand, increased amount of winter snow precipitation will lead to late snowmelt in spring, hence to a delay in the onset of the growing season (Wipf and Rixen, 2010). A late snow melt may affect the growth and reproductive success of early-growing plant species (Cooper et al., 2011; Khorsand Rosa et al., 2015), preventing the plants from taking advantage of the 24 -h photoperiod in late spring and the increased soil nutrient availability linked to a thicker snow cover.

In addition, increased summer air temperature can directly influence photosynthesis, nutrient cycling, decomposition processes and increased growing season length (Shaver et al., 1992; Schmidt et al., 2002; Oberbauer et al., 2007; Ernakovich et al., 2014). Hence, the interaction and magnitude of increased winter snow precipitation with increased summer air temperature will determine the length of the growing season, which may be critical for plant phenology and productivity (Fitter et al., 1999; Wipf and Rixen, 2010).
The aboveground production of arctic tundra plants and especially woody shrub species have increased in response to the positive trends in mean annual surface air temperature observed across the Northern-hemisphere (Tape et al., 2006; Elmendorf et al., 2012; Hollesen et al., 2015; Myers-Smith et al., 2015). Potentially, the so called "greening of the Arctic" could lead to climatic feedbacks as variations in vegetation cover may alter several abiotic factors such as surface albedo (Sturm et al., 2005), active soil layer depth, altering nutrient cycling and $\mathrm{C}$ storage (Mack et al., 2004). There is also evidence to support a positive relation between root growth and soil temperature, if other growth-related resources are not limiting (Pregitzer et al., 2000). The limited studies available for high latitudes suggest that root growth dynamics might also not directly respond to (small) changes in air temperature regimes. Positive trends of root growth in wet sedge tundra were linked to nutrient availability (Hill and Henry, 2011) and allocation of photosynthate from aboveground (Sullivan and Welker, 2005), which increased in response to increased surface air temperature. However, for some arctic sedge species, well adapted to cold soil temperatures, the length of the photoperiod, rather than air temperature, was identified as main driver of root elongation (Shaver and Billings, 1977).

The objective of this study was to quantify the short-term root dynamics, meaning the sensitivity of root growth (here meant as root elongation), in an arctic wetland to a moderate increase in winter snow precipitation and summer air temperature regimes. In situ measurements of root growth were carried out in a wetland in Disko Island (West Greenland) during the growing season 2014. A full factorial experimental set-up with snow fences and open top chambers (OTC) was used to simulate increased winter precipitation as snowfall, summer warming and their combination. We hypothesized that: (i) snow accumulation would have a negative effect on root growth as a consequence of late snowmelt and thus shorter growing season; (ii) summer warming would have at least a short-term positive effect on root growth to support plant uptake of nutrients; (iii) with the combined effect of experimentally increased summer warming and snow accumulation, summer warming would offset the delay in the onset of the growing season due to snow accumulation.

\section{MATERIALS AND METHODS}

\section{Site Description}

The study site is a wetland in Blæsedalen Valley, Disko Island, on the coast of West Greenland $\left(69^{\circ} 16^{\prime} \mathrm{N}, 53^{\circ} 27^{\prime} \mathrm{W}\right)$. Disko Island is located in the transitional zone between the low and high Arctic. According to meteorological data (1991-2011) of nearby Arctic Station (Hansen et al., 2006; Hollesen et al., 2015) mean annual air temperature is $-3.0 \pm 1.8^{\circ} \mathrm{C}(\mathrm{SD})$, the monthly means of the warmest (July) and the coldest (February-March) months are 7.9 and $-14.0^{\circ} \mathrm{C}$. The mean annual soil temperature at $5 \mathrm{~cm}$ depth is $-1.9^{\circ} \mathrm{C}$ and frozen soil conditions prevail from October to late May. At Arctic Station, $60 \%$ of the total annual precipitation is in the form of rain and the overall mean annual precipitation (rain 
and snow) has been estimated to be $\sim 400 \mathrm{~mm}$ (Hansen et al., 2006; Hollesen et al., 2015).

The study site is classified as a graminoid-dominated wetland located in the transition zone between the bioclimatic subzones $\mathrm{C}$ and D (Walker et al., 2002, 2005). The wetland has a peat layer of approximately $20-70 \mathrm{~cm}$ sitting on glacially rebedded sediments of volcanic basalt. The water table fluctuates from $20 \mathrm{~cm}$ below soil surface to $15 \mathrm{~cm}$ above (Nielsen et al., 2017).

The vegetation cover is dominated by the sedges Carex rariflora, Eriophorum angustifolium, Carex aquatilis ssp. stans, Carex gynocrates, and by the shrub Salix arctophila. Furthermore, in some areas Equisetum arvense is abundant. Pin-point vegetation cover analysis (Jonasson, 1988) was carried out on August 25th and 26th 2014.

\section{Experimental Set-Up}

A full-factorial experiment was established in July 2013 and included passive snow accumulation using snow fences, warming by OTCs and their combination. Six replicate blocks, each with a $14.7 \mathrm{~m}$-long and $1.5 \mathrm{~m}$-tall snow fence, were established to create snowdrifts on the leeward (South) side of the fences during winter (snow accumulation). The maximum ambient snow depth in 2014 was $80 \mathrm{~cm}$ and the snowdrift at the snow accumulation plots was $c a .30 \mathrm{~cm}$ deeper than ambient conditions. The site became snow-free on June 18th 2014, approximately a week later than at the ambient deposition side. On each side of the fences two plots $(2 \times 2 \mathrm{~m})$ were established ensuring an ambient snow cover depth at the windward side of the fences ( $6 \mathrm{~m}$ from the fence), as well as a maximum snow depth within the drift at the leeward side (3 m from the fence). Half of the plots were covered year-round by $3 \mathrm{~mm}$ thick polycarbonate hexagon OTCs $(35 \mathrm{~cm}$ tall, $150 \mathrm{~cm}$ in diameter at the base and $85 \mathrm{~cm}$ in diameter at the top) to increase air temperature during summer (Marion et al., 1997). The other half of the plots had ambient summer air regimes. The treatments were identified as: control (C), warming with OTCs (W), snow accumulation $(S)$ and the combination snow + warming with OTCs (SW), all in $n=6$ replicates (Supplementary Figure S1).

\section{Weather and Soil Parameters}

Air temperature at $2 \mathrm{~m}$ height was measured every $30 \mathrm{~s}$ and logged every $30 \mathrm{~min}$ by a meteorological station established at Blæsedalen Valley in July $2013\left(69^{\circ} 15^{\prime} 930^{\prime \prime} \mathrm{N}, 53^{\circ} 28^{\prime} 015^{\prime \prime} \mathrm{W}\right.$, $97 \mathrm{~m}$ asl). Temperature probes (Tinytag, Gemini Data Loggers, Chichester, United Kingdom) and soil moisture probes (HOBO, Onset Computer Corporation, Bourne, MA, United States) were installed in $5 \mathrm{~cm}$ depth in all the plots of three blocks. Temperature loggers, protected by waterproof plastic covers, were also placed $2 \mathrm{~cm}$ above the ground for measurements of air temperatures within the canopy. The soil moisture was recorded every $10 \mathrm{~min}$ and the temperature was recorded hourly.

Soil $\mathrm{pH}$ values at the wet sites were based on in situ measurements made during August 2015 by inserting the $\mathrm{pH}$ probe $\left(\mathrm{WTW}^{\mathrm{TM}}\right.$, SenTix ${ }^{\mathrm{TM}} 41 \mathrm{pH}$ electrode) directly into the ground at 2.5 and $7.5 \mathrm{~cm}$ (Table 1). Volume specific soil samples at $0-5$ and $5-10 \mathrm{~cm}$ depth were collected in August 2014 at the site and stored at $5^{\circ} \mathrm{C}$ until further analyses. Prior elemental analyses, the samples were oven dried at $60^{\circ} \mathrm{C}$ for $48 \mathrm{~h}$. The total $\mathrm{C}$ and $\mathrm{N}$ concentrations in the samples (Table 1) were measured in solid samples by Dumas combustion $\left(1020^{\circ} \mathrm{C}\right)$ on an elemental analyser (EA Flash 2000, Thermo Scientific, Bremen, Germany). Briefly, $10 \mathrm{mg}$ of grinded and dried material was weighed into tin combustion capsules for elemental analysis. Acetanilide (Merck, Darmstadt, Germany) and soil standards (Elemental Microanalysis, Okehampton, United Kingdom) were used for elemental analyser mass calibration.

\section{Minirhizotron Installation and Image Collection}

During July 2013, while setting up the snow fences, we installed 24 minirhizotron tubes made of high-grade transparent acrylic in order to take images of roots in each plot and follow the changes of root parameter over time in a non-destructive way. The tubes were inserted in the soil with a 45 degrees angle to the soil surface (Bragg et al., 1983); they had an inner diameter of $6.40 \mathrm{~cm}$ and a maximum length of $1 \mathrm{~m}$. Due to the presence of permafrost the maximum vertical depth reached by the bottom of the tubes ranged between a minimum of $c .25 \mathrm{~cm}$ and a maximum of $c$. $55 \mathrm{~cm}$, randomly. Foam pipes insulation were placed inside the tubes to protect from changes in temperature and moisture, and were only temporary removed while scanning. Tubes were closed on top with a rubber lid to protect the inner part from water leaks and debris. The part of the tubes protruding aboveground was painted in white to exclude sunlight and to avoid variations in the albedo during the periods of snow cover. In order to avoid an upwards movement of the tubes and a change in the angle due to the freezing - thawing cycles of the active layer, each tube was anchored to a metal bar placed in the soil.

One year after installation of the snow fences (i.e., summer 2014), images of roots were taken with a CI-600 root scanner (CID, Camas, WA, United States) at 600 dpi. The imaging campaigns took place five times during the growing season 2014 on July 2 nd and 22nd, August 13th, and September 8th and 17th.

\section{Image and Data Analysis}

During each campaign, three to five images were collected in each tube depending on its total length. The images were then analyzed with the software WinRhizoTron MF 2014a and XLRhizoTron (CRegent Instruments Canada Inc.). In order to be able to load and analyze all the images of a tube at once, the resolution was decreased to $400 \mathrm{dpi}$ (0.06 $\mathrm{mm}$ pixel size) so each image was

TABLE 1 | Overview of the main soil characteristics at the site $(n=6 \pm$ SE).

\begin{tabular}{|c|c|c|c|c|}
\hline & \multicolumn{4}{|c|}{ Soil depth (cm) } \\
\hline & $0-5$ & $\pm \mathrm{SE}$ & $5-10$ & $\pm \mathrm{SE}$ \\
\hline C (\%) & 21.08 & 1.50 & 18.65 & 0.63 \\
\hline N (\%) & 1.30 & 0.15 & 1.48 & 0.09 \\
\hline $\mathrm{C}: \mathrm{N}$ & 17.20 & 2.90 & 12.70 & 1.10 \\
\hline $\mathrm{pH}$ & 7.20 & 0.07 & 6.90 & 0.09 \\
\hline Bulk density $\left(\mathrm{g} \mathrm{cm}^{-3}\right)$ & $0.04^{\mathrm{a}}$ & 0.01 & 0.12 & 0.04 \\
\hline
\end{tabular}

aThe low bulk density indicates that this depth interval was mainly dominated by undecomposed litter and mosses. 
$19.6 \mathrm{~cm}$ in width and $21.6 \mathrm{~cm}$ in length. A total of 308 images were analyzed. The output of the image software provided information on root length, number, and average diameter for each single root in each campaign as well as the surface area calculated assuming perfectly round roots. It was not possible to separate the roots into different plant species. The disappearance of roots between campaigns was indicated as "gone roots" rather than "dead roots" since it was not possible to confirm the latter condition. Moreover, root mortality was not likely to be assessed during a single growing season. For this reason, the final calculations included both the "alive roots" and the "gone roots," where "gone roots" represented $1.6 \%$ of the total number. All roots were clustered in vertical soil depth increments of $10 \mathrm{~cm}$ from the soil surface to the bottom of the tubes, and the calculations took into account the 45 degrees angle used to insert the tubes in the soil. Across all the treatment plots, 20 and $66 \%$ of the tubes randomly reached the 50-60 and 40-50 cm vertical soil depth, accordingly these soil depth intervals were excluded from the analyses by depth. Consequently, the soil depth of 0-40 cm was chosen to assess root properties and dynamics over the soil profile represented by $86 \%$ of the tubes.

The results are reported for each measurement campaign as: total number of roots per tube $(0-40 \mathrm{~cm}$ depth), total root length and surface area (as sum of each single root length or surface area) were estimated per tube area $\left(\mathrm{cm}^{2}\right)$ based on the specific length of each tube belowground, and average root diameter is reported by tube.

Total root length growth was estimated as daily rates as follows:

$$
L_{\mathrm{g}}=\frac{\left(L_{2}-L_{1}\right)}{T_{\mathrm{d}}}
$$

where $L_{\mathrm{g}}$ is the root length growth rate $\left(\mathrm{mm} \mathrm{cm}^{-2} \mathrm{~d}^{-1}\right), L_{2}$ and $L_{1}$ are the root lengths measured at two consecutive sampling dates and $T_{\mathrm{d}}$ is the number of days between sampling dates (Sullivan and Welker, 2005).

The root growth at each vertical soil depth is reported as maximum root growth calculated as the rate per tube surface area between the 2 nd of July and the 13 th of August $\left(\mathrm{mm} \mathrm{cm}^{-2} \mathrm{~d}^{-1}\right)$.

\section{Fine Root Biomass}

At the time of the minirhizotron installation the soil cores excavated ( $n=24$ ) were brought back to the laboratory, split into specific vertical soil depths (O-horizon, 0-10, 10-20, 20-30, 30$40,40-50$, and $50-60 \mathrm{~cm})$ and stored at $4^{\circ} \mathrm{C}$ until manual root sorting. The fine roots $(<2 \mathrm{~mm})$ were separated from the soil by forceps, gently washed, oven-dried at $55^{\circ} \mathrm{C}$ for $48 \mathrm{~h}$ and weighed to estimate the dry weight (DW).

\section{Root Ingrowth Bags for Fine Root Production}

In July 2013, 12 soil cores ( $4.5 \mathrm{~cm}$ diameter) were collected with a 45 degrees angle adjacent to the experimental blocks in an area with comparable vegetation cover. Back in the laboratory, the samples were split into $0-5,5-10$, and $10-15 \mathrm{~cm}$ vertical soil depths and stored at $4^{\circ} \mathrm{C}$. Within 2 days after collecting the samples, all the roots present in the soil were manually removed with forceps. Due to insufficient soil conditions (too wet and full of organic material), coarse sand was collected from the same area to mix into the ingrowth bags. The sand was first washed with distilled water and sieved through $0.5 \mathrm{~mm}$ mesh. Then, in order to avoid introducing microbial communities not belonging to the "wetland area," it was set for 30 min into a glass vessel with a solution of distilled water (2 1) and hydrochloric acid (3.7\%, $200 \mathrm{ml}$ ) and finally rinsed several times with distilled water. The ingrowth bags were made of synthetic textile designed with a length of $21 \mathrm{~cm}$, a width of $4.5 \mathrm{~cm}$ and a mesh size of $1 \mathrm{~mm}$. The bags were filled with root-free soil and sand homogeneously mixed together $(1: 1)$ to reach the original fresh weight of each portion of the soil core. The three depth-specific subsamples of sorted soil and sand were placed into the ingrowth bags following the exact depth order and they were kept separated by inserting a small piece of mesh cloth in between each soil layer matrix. Prior to installation, the bags were stored in the fridge at $4^{\circ} \mathrm{C}$. During the same month the ingrowth bags were placed in the soil at a 45 degrees angle within each control (C) and snow accumulation (S) plot $(n=6) 25 \mathrm{~cm}$ from the minirhizotron tubes. In September 2014, the bags were retrieved manually by using a knife. In the laboratory, the samples were separated into each depth-specific section and stored in the freezer at $-18^{\circ} \mathrm{C}$ until the time of root sorting. Once the soil samples were thawed at $5^{\circ} \mathrm{C}$, the fine roots ( $\leq 2 \mathrm{~mm}$ diameter) were manually sorted, washed and oven-dried at $55^{\circ} \mathrm{C}$ for $48 \mathrm{~h}$. Live roots were identified by color and elasticity whenever possible (Oliveira et al., 2000), although the preservation of roots in the cold Arctic made this visual inspection difficult. The fine root biomass, which colonized the volume of the ingrowth bags during a year, was used to estimate the belowground net root productivity per soil area. As for the results from the minirhizotron tubes, the calculation of root productivity took into account the 45 degrees angle, and the root depths reported refer to vertical depths.

\section{Fine Root Turnover}

Root system turnover was calculated based on the root ingrowth bags (0-15 cm soil depth) as belowground net primary production $\left(\mathrm{g} \mathrm{m}^{-2}\right)$ divided by the initial standing belowground biomass of fine roots $\left(\mathrm{g} \mathrm{m}^{-2}\right)$ (Gill and Jackson, 2000). The belowground biomass used for the calculations included the O-horizon (ca. $5 \mathrm{~cm}$ ) and the top $0-10 \mathrm{~cm}$ soil depth.

The turnover was estimated only for the roots that grew at ambient condition (C), despite the fact that ingrowth bags were placed also in plots with snow accumulation as main treatment (S). This was done in order to avoid biases derived from different initial conditions between the time of estimation of fine root biomass, prior to the beginning of the $\mathrm{S}$ treatment, and the fine root production, which was estimated a year after the snow accumulation experiment was initiated. A timeline of the installations and the measurements carried out at the site can be found in Supplementary Table S1.

\section{Statistical Analyses}

Possible differences in initial root biomass between the two sides of the snow fences, i.e., the control and snow accumulation plots were tested with a two samples $t$-test. 
Significant total and depth-specific differences of fine root productivity, derived from the ingrowth bags, between single treatment snow accumulation (S) and ambient snow (C) were tested with a general linear model (GLM).

The effects of the climate manipulations on the root parameters monitored with minirhizotrons were quantified by taking into account both temporal (during the season) and spatial (over the soil profile) changes. Unless stated otherwise, these analyses were done using the PROC MIXED procedure of SAS software version 9.3 (SAS Institute Inc., 2013) and the SAS Enterprise Guide version 7.1. Least squares post hoc tests on significant treatment effects were performed to investigate all pairwise differences of least squares means among factors and Bonferroni adjusted $P$-values were used for multi-comparison correction. Model reduction was done by stepwise exclusion of non-significant terms starting from the highest degrees of interaction $(P>0.2)$.

When necessary, the data were log or square root transformed in order to meet homogeneity of variance and normality. The significant treatment effects are based on $P \leq 0.05$, but tendencies toward significance $(P \leq 0.10)$ are also presented. Further, the results of the $F$ tests are reported together with the numerator and denominator degrees of freedom, indicated, respectively, by the first and second subscript values.

The error bars shown are one standard error of the mean (SE). In the figures, tendencies and significant treatment effects are indicated by: ${ }^{\dagger} P \leq 0.1,{ }^{*} P \leq 0.05,{ }^{* *} P \leq 0.01$, and ${ }^{* * *} P \leq 0.001$. All the figures were created using SigmaPlot 13.0 (Systat Software, Inc., San Jose, CA, United States).

\section{Statistical Tests on Temporal Changes}

Overall changes in response to the climate manipulation in root number, length, surface area and growth per tube area as well as averaged root diameter over the whole tube were quantified for the growing season. Accordingly, we used an ANOVA mixed model with random effects "block" and "block $\times$ snow" (where "snow" referred to the side of the block with experimentally increased snow depth) and with date as day of the year (DOY) of each measurement campaign as repeated effect and "plot" as subject identifier. The model included DOY, S and warming (W) as fixed effects in a factorial design. This means that, if for example the outcome of the model indicates warming (W) as significant main effect, all the plots with experimentally increased air temperature (W and SW) are different from plots with ambient air conditions (C and S).

The same ANOVA mixed model, without DOY as fixed factor, was used to test treatment effects on air temperature within the canopy, soil temperature and soil moisture at $5 \mathrm{~cm}$ depth.

\section{Statistical Tests on Spatial Changes}

To test the treatment effects on the probability of finding roots at specific vertical depth intervals $(0-10,10-20,20-30$, and 30$40 \mathrm{~cm}$ ), we ran a logistic mixed model on the root number data obtained from the image analysis and included "block" as random effect. This analysis was done using the GLIMMIX procedure of SAS 9.3 (SAS Institute Inc., 2013).

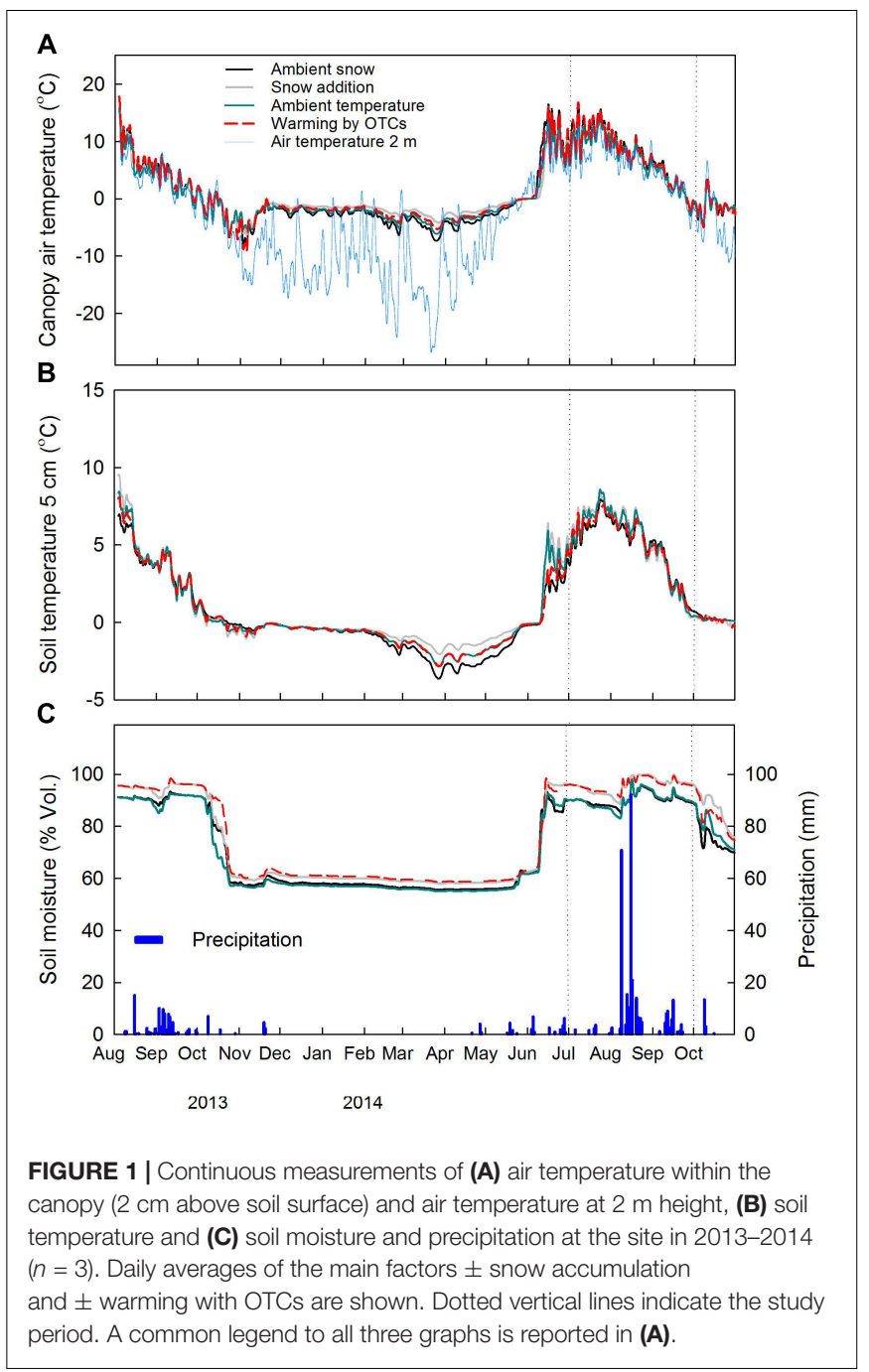

In order to analyze the climate effects on the roots distribution (total number of roots, their lengths and maximum root growth) over the soil profile, we ran an ANOVA mixed model for each measurement campaign. The model included "block" and "block $\times$ snow" as random effects, "soil depth" as repeated effect and "plot" as subject identifier. The fixed effects were soil depth, $\mathrm{S}$ and $\mathrm{W}$ in a factorial design.

The overall treatment effects on root number and length distribution were quantified by including in the above-mentioned ANOVA mixed model all the measurement campaigns and "DOY $\times$ plot" as random factor to account for time repetition.

Maximum root growth in each depth interval $\left(\mathrm{mm} \mathrm{cm}^{-2} \mathrm{~d}^{-1}\right)$ and aboveground plant cover data (\%) were assessed with an ANOVA mixed model with only the random effects.

\section{RESULTS}

\section{Soil Temperature and Moisture}

During the growing season 2014 (21st of May-31st of September), the daily average air temperature within the canopy 
TABLE 2 | Vegetation cover identified in August 2014 at each treatment plot here reported as average with standard errors $( \pm$ SE: $n=6)$.

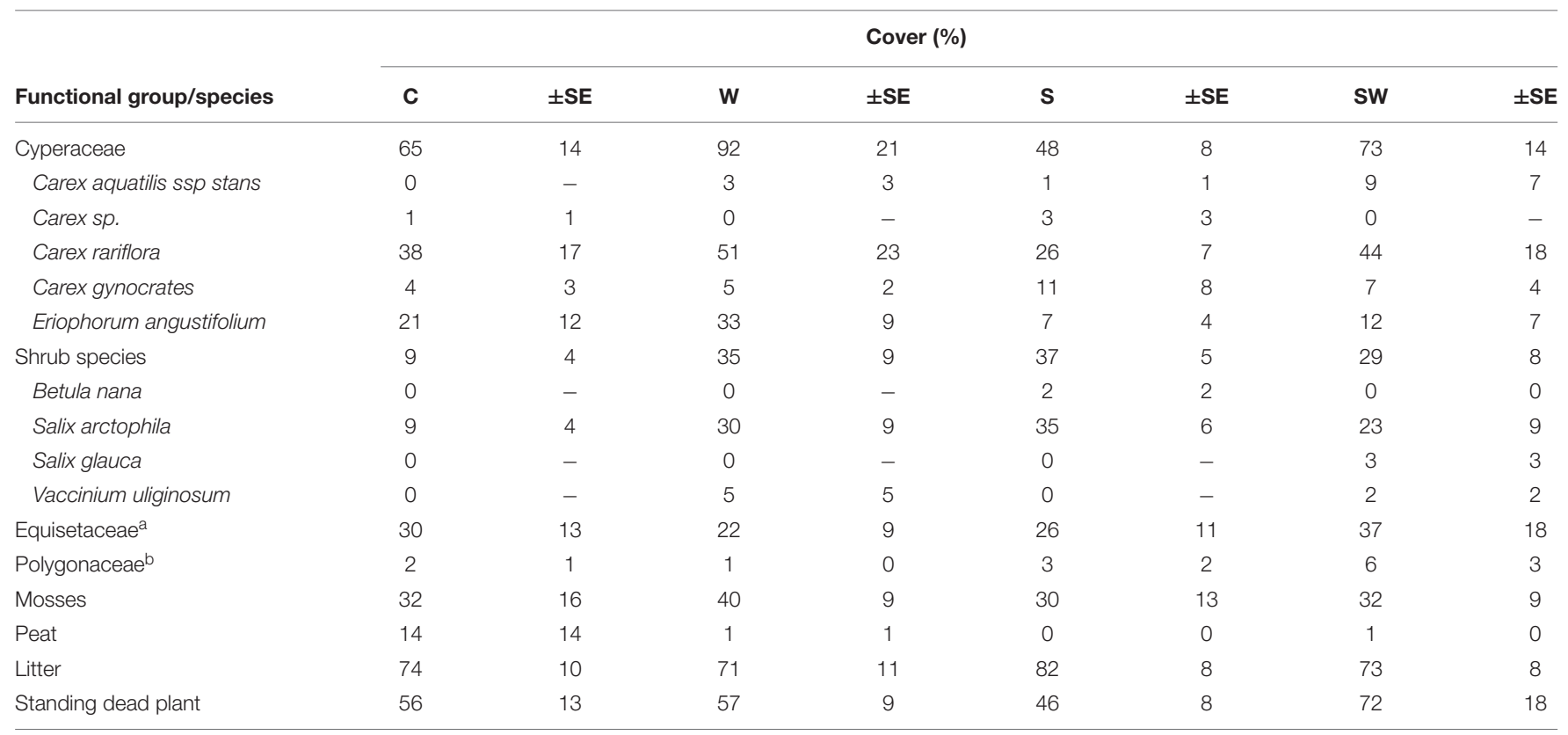

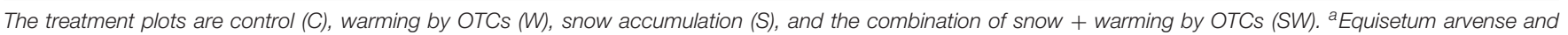
Equisetum scirpoides ${ }^{b}$ Bistorta vivipara

was significantly reduced by snow accumulation $\left(-0.9^{\circ} \mathrm{C}\right)$ $\left(F_{1,9}=10.34, P=0.01\right)$ and increased by warming with OTCs $\left(+0.9^{\circ} \mathrm{C}\right)\left(F_{1,9}=8.91, P=0.02\right)$ (Figure $\mathbf{1 A}$ and Supplementary Figure S2A). During the same period, no significant treatment effect was noticed for the soil temperature at $5 \mathrm{~cm}$ depth (Figure 1B and Supplementary Figure S2B). The effect of increased snow depth on air temperature within the canopy and at $5 \mathrm{~cm}$ soil depth was detected in the measurements during winter time (21st November 201320th May 2014), as expected from the experimental setup. Snow accumulation significantly increased air temperature within the canopy by $1.4^{\circ} \mathrm{C}\left(F_{1,9}=5.39, P=0.05\right)$, and tended to increase soil temperature at $5 \mathrm{~cm}$ depth by $0.6^{\circ} \mathrm{C}$ $\left(F_{1,9}=4.01, P=0.08\right)$. No significant treatment effect was instead detected on the continuous measurements of soil moisture at $5 \mathrm{~cm}$ soil depth (Figure 1C and Supplementary Figure S2C).

\section{Aboveground Plant Cover}

A year after the beginning of the experiment, the total aboveground cover of sedge species was 39\% higher in plots with warming by OTCs $\left(F_{1,11}=4.74, P=0.05\right)$ (Table 2 ).

Furthermore, the total cover of shrubs was significantly higher with the interaction of warming by OTCs and snow accumulation $\left(F_{1,10}=8.61, P=0.015\right)$. No other differences between treatments were detected.

\section{Soil Cores and Ingrowth Bags}

\section{Root Biomass, Productivity and Turnover}

Depth-specific root biomass $(\leq 1 \mathrm{~mm}$ diameter) was estimated based on the soil cores excavated during minirhizotrons

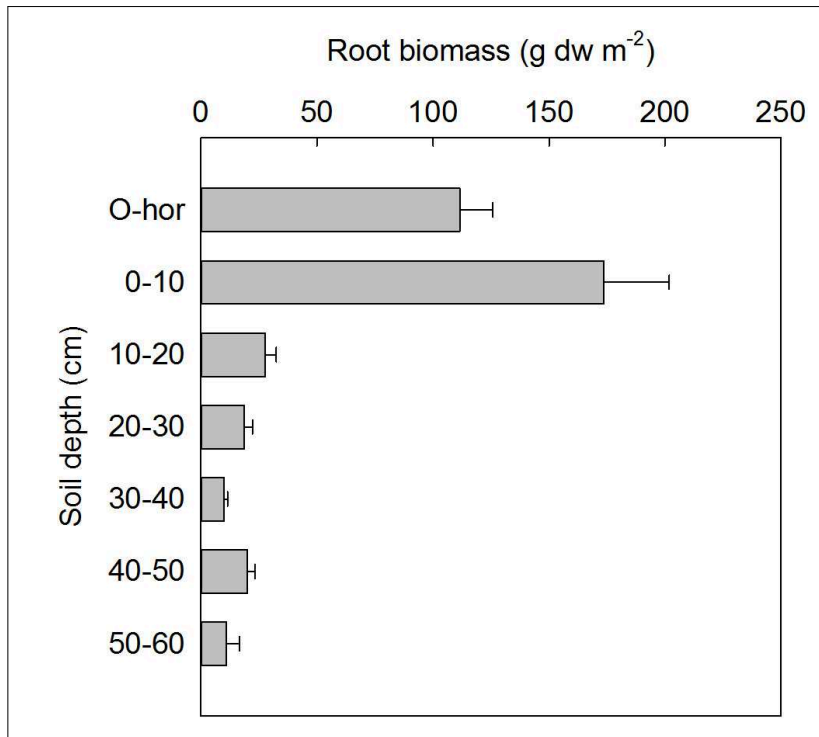

FIGURE 2 | Root biomass (mean \pm SE) based on soil samples from all plots in July 2013 at the time of minirhizotron installation $(n=24)$.

installation at each plot in 2013 (Figure 2), therefore these results are representative of the initial standing root biomass at the site in ambient conditions. The largest root biomass was found in the $0-$ $10 \mathrm{~cm}$ soil depth with a maximum value of $174 \pm 28 \mathrm{~g} \mathrm{dw} \mathrm{m}^{-2}$, and roots were found down to $60 \mathrm{~cm}$ soil depth. There was no significant difference in the initial root biomass between the two sides of the snow fences.

By adding sand to the ingrowth bags, the soil texture and nutrient concentration changed as compared to the initial 


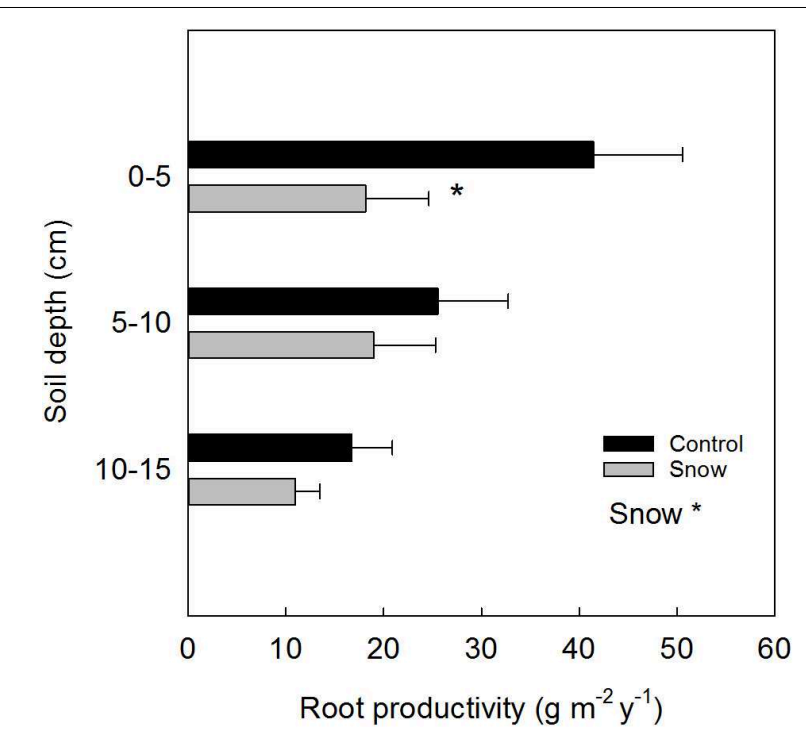

FIGURE 3 | Relative depth-specific fine root productivity (mean \pm SE) estimated from ingrowth bags placed at control and at snow accumulation plots $(n=6)$. Significant treatment effects are indicated by a $* P \leq 0.05$.

characteristics of the soil. For this reason, the results reported are presented as "relative" fine root production. A year after the installation of ingrowth bags, in 2014, in plots with snow accumulation as main treatment (S), the relative production of fine root biomass (Figure 3) was reduced in the $0-5 \mathrm{~cm}$ soil depth by $56 \%\left(F_{1}=4.96, P=0.05\right)$. Overall, snow accumulation reduced the total fine root productivity $(0-15 \mathrm{~cm})$ by $42 \%\left(F_{1}=4.11\right.$, $P=0.05)$. Within the control plots a tendency toward less fine root production was found in the $10-15 \mathrm{~cm}$ soil depth, as compared to the upper 0-5 cm (Tukey's adjustment for multiple comparisons: $P=0.09$ ).

Based on the relative root production derived from the ingrowth bags (year 2014) at the control plots (C) and the initial standing root biomass at the site estimated by the soil cores (year 2013), the root turnover at ambient conditions was $0.29 \pm 0.048 \mathrm{y}^{-1}$ over the $0-15 \mathrm{~cm}$ soil depth.

\section{Minirhizotrons}

\section{Treatment Effects on Seasonal Root Parameters and Growth}

The results of image analysis show a strong seasonality (DOY: $\left.F_{4,83.9}=41.63, P<0.001\right)$ and clear trends in the total number of roots, total root length, total surface root area and average diameter estimated by minirhizotrons (Figure 4). In contrast, the averaged single root length per tube area was not altered by any of the treatments and did not show any seasonality (Supplementary Table S2). All the parameters investigated, except for the average diameter, increased in all the treatments during the season reaching a maximum at the beginning of September (Figures 4A-C). The decreasing trends observed during the last campaign are due to missing measurements in block 1 (because of adverse weather conditions) rather than an ecological process. However, the abundant presence of roots in block 1, in comparison to the other replicate blocks, and the missing measurement during the last campaign did not alter the outcome of the statistical analyses, as these aspects are taken into account by the model used (Zuur et al., 2009).

The average root diameter was highest during the first measurement campaign in July across all treatments $(0.67 \pm 0.02 \mathrm{~mm})$ and followed by a decreasing trend until the last campaign in September (Figure 4D). Plots with experimental summer warming by OTCs showed a tendency of increased root number (49\%) and length (38\%) over the season (Table 3). The increased snow accumulation instead, significantly reduced the diameter of the roots by $14 \%$ (Table 3) as also indicated by the significant interaction snow $\times$ warming $\left(S: t_{18.9}=3.48\right.$, $P=0.015)$.

The number of roots significantly increased during the last two campaigns with warming with OTCs (Table 4). The increase ranged between $39 \%$ on September 8 th and $53 \%$ on September 17 th. During the same campaigns, positive tendencies were also detected in total root lengths, which increased significantly (39\%) on September 8th (Table 4). Root diameter significantly decreased in plots with increased snow deposition (Table 4) from July 22nd (17\%) to September 17th (24\%).

The rate of root growth at ambient conditions peaked between July 24th and August 13th, the same pattern was observed among all treatments (Figure 5). Warming with OTCs tended to increase root growth $\left(F_{1,10}=4.27, P=0.066\right)$ between August 13th and September 8 th, in agreement with the significant increase in total root length observed at the beginning of September.

\section{Root Distribution Along the Soil Profile}

The root image analyses showed that the distribution of roots within the soil profiles was not always the same among treatment replicates. It was therefore of interest to understand whether the presence or absence of roots at specific soil depths was related to the effects of the treatments or other factors. The results of the logistic model confirmed that warming by OTCs significantly increased the presence of roots in the deeper layers of the soil profile (20-30 cm: $F_{1,98}=2.92, P=0.09 ; 30-40 \mathrm{~cm}: F_{1,98}=9.30$, $P=0.003)$.

Across the entire soil profile $(0-40 \mathrm{~cm})$, the maximum number of roots and length were found in the $0-20 \mathrm{~cm}$ depth (data not shown) and in each sampling date, they consistently decreased with soil depth (Table 5). During the last two measurement campaigns root length significantly increased with warming with OTCs by 62 and 74\%, while the number of roots significantly increased by $59 \%$ during the last campaign (Table 5). Further tendencies toward a positive experimental warming effect on these parameters are reported in Table 5.

No significant effect of the climate manipulation was detected either on the number of roots nor on their total length within the single soil depth intervals.

The overall effects of the climate manipulations on root number and length were also estimated taking into account the possible differences in spatial distribution across the soil profile without focusing on the seasonal patterns. The total number of roots and length significantly increased with 

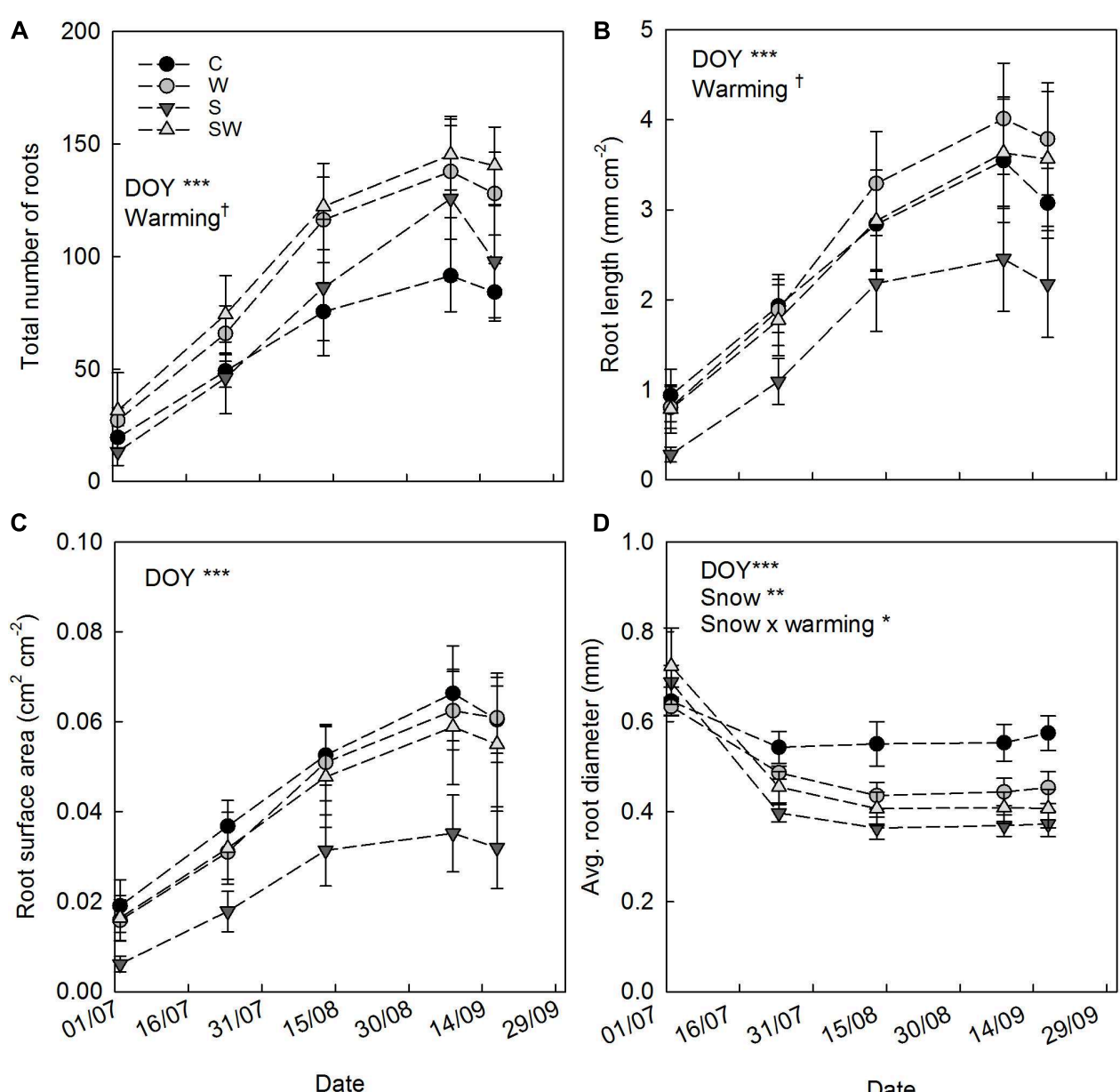

Date

Date

FIGURE 4 | Root parameters measured over the growing season 2014 (mean \pm SE). (A) Total root number by tube. (B) Total root length per tube area. (C) Total root surface area per tube area. (D) Average root diameter by tube. Tendencies and significant repeated treatment effects are reported for each parameter and indicated by ${ }^{\dagger} P \leq 0.1,{ }^{*} P \leq 0.05,{ }^{* *} P \leq 0.01$, and ${ }^{* * *} P \leq 0.001$. In legend: control (C), warming by OTCs $(\mathrm{W})$, snow accumulation (S), and snow + warming by OTCs (SW).

experimental warming with OTCs over the whole soil profile by $41 \%\left(F_{1,22.2}=4.45, P=0.046\right)$ and $54 \%\left(F_{1,22.4}=5.14\right.$, $P=0.03)$. The values of averaged single root length in each soil depth interval are reported in Supplementary Table S3.

The depth-specific root length growth estimated at the same soil depth intervals showed a maximum growth within the $0-20 \mathrm{~cm}$ soil depth in all the treatment plots $\left(0.08 \pm 0.01 \mathrm{~mm} \mathrm{~cm}^{-2} \mathrm{~d}^{-1}\right.$ average across treatments) which decreased significantly (Depth: $F_{3,63}=16.87, P<0.001$ ) down to $40 \mathrm{~cm}$ soil depth (Figure 6). Root growth at $20-30 \mathrm{~cm}$ depth significantly increased by $71 \%$ with warming by OTCs $\left(F_{1,9.63}=6.58, P=0.03\right)$.

\section{DISCUSSION}

The results presented in this study quantify the short-term effects (1 year) of snow accumulation, summer warming and their combination on root production and phenology in an arctic wetland. A key observation was the fast response of root growth to increased snow deposition and summer air warming, despite the fact that an actual temperature increase was detected only at the canopy. This highlights the importance of investigating the initial responses of the belowground root biomass to changes in precipitation (as snow) and temperature regimes, bearing in mind that changes in root growth and depth reveal an important seasonal dynamic that may affect the overall ecosystem $\mathrm{C}$ budget and nutrient cycling.

\section{Ambient Root Biomass, Production and Turnover}

The fine root biomass estimates at ambient conditions as well as relative root production from ingrowth cores were consistent with values previously reported per unit ground area in arctic wetlands (Sullivan et al., 2007, 2008; Iversen et al., 2015). Fine root production was $84 \mathrm{~g} \mathrm{~m}^{-2}$ in the $0-15 \mathrm{~cm}$ vertical soil depth with a dry fine root biomass of $285 \mathrm{~g} \mathrm{~m}^{-2}$. If steady state is assumed, as suggested in Sullivan et al. (2008), the mean residence time of fine roots in this study was about 3.4 years. In line with 
TABLE $3 \mid P$-values of treatment effects on root parameters over the measurement season 2014 (ANOVA repeated mixed model).

\begin{tabular}{llccc}
\hline Variables & Fixed effects & DF & F-value & $\boldsymbol{P}$-value \\
\hline Total number & DOY & 4,84 & 152.17 & $<\mathbf{0 . 0 0 1 \uparrow}$ \\
& W & $1,21.8$ & 3.04 & 0.095 \\
Total length $\left(\mathrm{mm} \mathrm{cm}^{-2}\right)$ & DOY & 4,80 & 123.04 & $<\mathbf{0 . 0 0 1 \uparrow}$ \\
& W & $1,20.9$ & 2.96 & 0.100 \\
& S & $1,20.9$ & 0 & 0.970 \\
Total surface area & DOY $\times$ W & 4,80 & 3.43 & $\mathbf{0 . 0 1 2} \uparrow$ \\
cm $^{2}$ cm $^{-2}$ ) & DOY & $4,76.1$ & 117.32 & $<\mathbf{0 . 0 0 1 \uparrow}$ \\
Average diameter (mm) & DOY & $4,75.4$ & 54.89 & $<\mathbf{0 . 0 0 1} \downarrow$ \\
& W & $1,18.9$ & 0.82 & $\mathbf{0 . 3 7 6}$ \\
& S & $1,18.9$ & 6.98 & $\mathbf{0 . 0 1 6} \downarrow$ \\
& DOY $\times$ S & $4,75.4$ & 6.45 & $<\mathbf{0 . 0 0 1} \downarrow$ \\
& W $\times$ S & $1,18.8$ & 5.22 & $\mathbf{0 . 0 3 4} \downarrow$ \\
\hline
\end{tabular}

The fixed effects are day of the year (DOY), warming by OTCs (W), snow accumulation (S), and their interactions. Significant $P$-values are reported in bold together with arrows indicating either a significant negative ( $\downarrow$ ) or positive ( $\uparrow$ ) treatment effect.

TABLE $4 \mid P$-values of main treatment effects and interactions on root parameters during each measurement campaign (ANOVA mixed model).

\begin{tabular}{|c|c|c|c|c|c|}
\hline \multirow[b]{2}{*}{ Date (2014) } & \multirow[b]{2}{*}{$\begin{array}{l}\text { Fixed } \\
\text { effect }\end{array}$} & \multicolumn{4}{|c|}{ Parameters } \\
\hline & & Number & Length & $\begin{array}{c}\text { Surface } \\
\text { area }\end{array}$ & Diameter \\
\hline \multirow[t]{3}{*}{02 July } & W & 0.096 & 0.119 & 0.126 & 0.814 \\
\hline & S & - & - & - & 0.198 \\
\hline & $W \times S$ & - & - & - & 0.637 \\
\hline \multirow[t]{3}{*}{22 July } & W & 0.165 & 0.097 & 0.100 & 0.965 \\
\hline & S & - & - & - & $0.005 \downarrow$ \\
\hline & $W \times S$ & - & - & - & $0.050 \downarrow$ \\
\hline \multirow[t]{3}{*}{13 August } & W & 0.111 & 0.090 & 0.130 & 0.337 \\
\hline & S & - & - & - & $0.008 \downarrow$ \\
\hline & $W \times S$ & - & - & - & $0.042 \downarrow$ \\
\hline \multirow[t]{3}{*}{08 September } & W & $0.043 \uparrow$ & $0.039 \uparrow$ & 0.076 & 0.310 \\
\hline & S & - & - & - & $0.004 \downarrow$ \\
\hline & $W \times S$ & - & - & - & $0.036 \downarrow$ \\
\hline \multirow[t]{3}{*}{17 September } & W & $0.020 \uparrow$ & 0.080 & 0.237 & 0.254 \\
\hline & S & - & - & - & $0.004 \downarrow$ \\
\hline & $W \times S$ & - & - & - & $0.049 \downarrow$ \\
\hline
\end{tabular}

The fixed effects are warming by OTCS (W), snow accumulation (S), and their interactions. Significant $P$-values are reported in bold together with arrows indicating either a significant negative $(\downarrow)$ or positive $(\uparrow)$ treatment effect. For the root parameters: number, length and surface area the $P$-values are reported only for $W$ due to exclusion of non-significant $(P>0.2)$ fixed effects from the model.

this estimate, a mean life-span $>3$ years has been observed in temperate grasslands (Mommer et al., 2015) characterized by low nutrient availability and low root mortality per year (Van Der Krift and Berendse, 2002; Arndal et al., 2017).

However, it is important to acknowledge that the absolute numbers may be only a rough estimation of the root production at the site. This was because the soil characteristics inside the ingrowth bags were changed by adding sand, and therefore

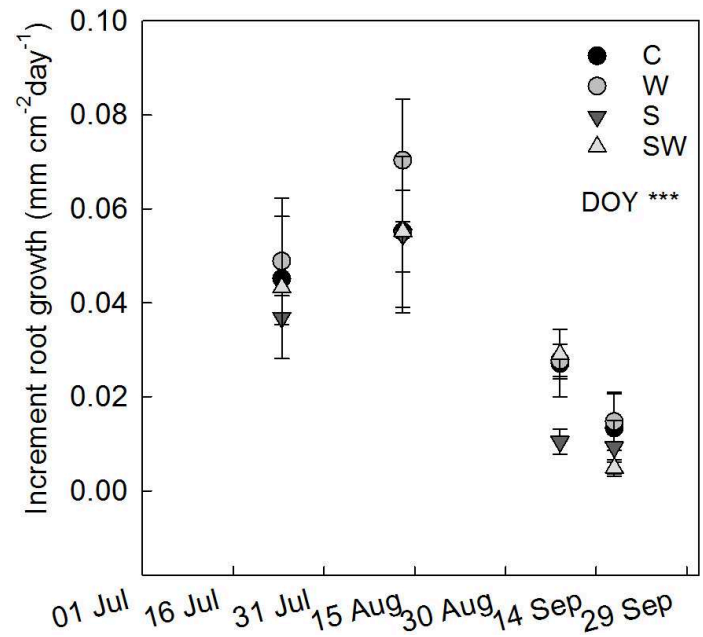

FIGURE 5 | Increment of cumulative root length growth between consecutive measurement campaigns (mean $\pm \mathrm{SE}$ ) estimated at each treatment plot: control (C), warming by OTCs $(\mathrm{W})$, snow accumulation (S), and snow + warming by OTCs (SW). The significant effect of day of year (DOY) is indicated by ${ }^{* * *} P \leq 0.001$.

changes in soil bulk densities, nutrient concentration and the reduced root competition in the soil volume inside the bags may have altered the degree of colonization of the finest roots.

A fine root turnover at ambient conditions of $0.29 \pm 0.048 \mathrm{y}^{-1}$ was in the range of previously estimated turnovers of high latitudes grasslands, which are considered the lowest reported turnover rates across different ecosystems (Lauenroth and Gill, 2003). Gill and Jackson (2000) reported a mean root turnover for graminoids at high latitudes of $0.29 \mathrm{y}^{-1}$ across 16 studies, and accordingly Iversen et al. (2015) estimated an averaged root lifespan of $>5$ years across tundra ecosystems mainly dominated by graminoids. In these systems, slow root turnover rates represent an effective advantage to increase the mean residence time of plant nutrients (Berendse and Aerts, 1987). We did not estimate root turnover based on the minirhizotron data as earlier studies suggest a waiting time between 6 months (Hendrick and Pregitzer, 1996) and 4 years (Iversen et al., 2008), to reach quasiequilibrium in root turnover (Iversen et al., 2012). Clearly, the values of root turnover rates estimated at ambient conditions provide the background knowledge to assess the current status of an ecosystem, which over time, may change in order to adapt to the projected climatic scenarios. Our observations of aboveground plant cover at the experimental plots highlighted a significantly higher amount of sedges (39\%) in plots exposed to experimental warming with OTCs. Although, sedges have higher root turnover rates compared to shrub species (Gill and Jackson, 2000), we could expect an accumulation of litter in the deeper layers of the soil as the deeper-rooted sedges will produce more root litter deeper in the soil profile. Due to the low temperature, decomposition is also expected to be low. Hence reduced root decomposition rates may lead, in the long-term to increased $\mathrm{C}$ storage, with implications for the overall ecosystem $\mathrm{C}$ and $\mathrm{N}$ dynamics. 
TABLE 5 | P-values for differences of Least Squares Means (LSmeans) for main effects in each measurement campaign after exclusion of non-significant fixed effects from the model.

\begin{tabular}{|c|c|c|c|c|c|c|c|c|c|c|}
\hline \multirow{2}{*}{$\begin{array}{l}\text { Date (2014) } \\
\text { Fixed effects }\end{array}$} & \multicolumn{2}{|c|}{2 July } & \multicolumn{2}{|c|}{22 July } & \multicolumn{2}{|c|}{13 August } & \multicolumn{2}{|c|}{08 September } & \multicolumn{2}{|c|}{17 September } \\
\hline & Depth & $\mathbf{w}$ & Depth & $\mathbf{w}$ & Depth & $\mathbf{w}$ & Depth & w & Depth & $\mathbf{w}$ \\
\hline \multicolumn{11}{|l|}{ Parameters } \\
\hline Length & $0.002 \downarrow$ & 0.071 & $<0.001 \downarrow$ & $>0.1$ & $<0.001 \downarrow$ & 0.096 & $<0.001 \downarrow$ & $0.041 \uparrow$ & $<0.001 \downarrow$ & $0.026 \uparrow$ \\
\hline Number & $0.001 \downarrow$ & $>0.1$ & $<0.001 \downarrow$ & $>0.1$ & $<0.001 \downarrow$ & $>0.1$ & $<0.001 \downarrow$ & 0.075 & $<0.001 \downarrow$ & $0.018 \uparrow$ \\
\hline
\end{tabular}

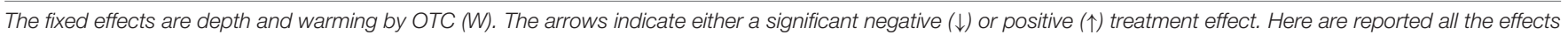
with $P \leq 0.1$ and significant treatment effects $(P \leq 0.05)$ are noticeable in bold.

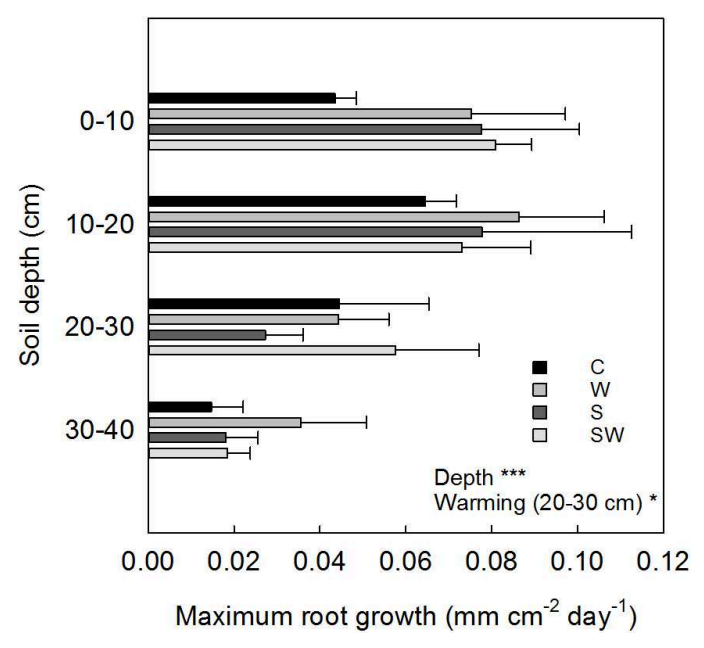

FIGURE 6 | Averaged values estimated for each treatment (mean \pm SE) at each soil depth interval of maximum root growth per tube area. Significant treatment effects are indicated by ${ }^{*} P \leq 0.05$ and ${ }^{* * *} P<0.001$.

\section{Responses to Increased Snow Deposition}

Overall, root dynamics at the snow accumulation plots are complex due to the combined effects of snow accumulation on soil temperature during wintertime (Figure 1), timing of thaw and low air temperature within the canopy during the growing season (Supplementary Figure S2).

In accordance to our hypothesis (i), snow accumulation as main treatment $(\mathrm{S})$ consistently reduced the relative fine root production in the $0-15 \mathrm{~cm}$ depth. At these plots, we estimated an annual fine root production of $48 \mathrm{~g} \mathrm{~m}^{-2}$. The snowdrift behind the fences delayed the onset of the growing season of about a week by shading the aboveground vegetation from sunlight and significantly reducing the air temperature within the canopy. Hence, this might have affected the development of belowground biomass by means of reduced photosynthetically fixed C allocation from aboveground (Leffler and Welker, 2013). Consequently, reduced fine root biomass production could derive from the production of lighter and thinner roots (Figure 4D) than those under ambient snow precipitation, to preserve the capacity of nutrient uptake under C-limited conditions (Van Der Krift and Berendse, 2002).
On the other hand, arctic plant species are well-adapted to cold temperatures (Iversen et al., 2015) and a positive correlation between root production and soil temperature is species-specific and becomes less relevant at high latitudes (Abramoff and Finzi, 2015; Blume-Werry et al., 2016; Sloan et al., 2016; Arndal et al., 2017). An alternative explanation for the observed results could be that due to better insolation under the thicker snow layer, increased soil temperatures (Figure 1) might have stimulated $\mathrm{N}$ mineralization (Semenchuk et al., 2015), thereby increasing plant-available $\mathrm{N}$ at the onset of the growing season (Jonasson et al., 1999; Schmidt et al., 2002; Schimel et al., 2004; Buckeridge and Grogan, 2010). In accordance, the plants might have changed their rooting strategy by reducing the allocation to roots in accordance to the "functional equilibrium model" (Poorter and Nagel, 2000). In the present study, it was not possible to estimate nutrient availability during spring thaw and further analyses are recommended to link depth-specific root growth and nutrient availability. The consistently small roots diameters we observed (Figure 4D and Table 4) may also suggest that increased snow depth (as single factor and in combination with warming) have favored the belowground growth of plant species, e.g., shallowrooted shrubs, with thin absorptive roots for a fast acquisition of nutrients (Kong et al., 2016), rather than triggering a change in rooting strategy. This is well in accordance to previous studies in high latitudes, which observed early-season growth of shrub root biomass simultaneously with increased nutrient availability in the surface soil (Wang et al., 2017).

\section{Responses to Increased Summer Air Temperature}

The results of the measurement campaign during the growing season 2014 showed, in accordance with our hypothesis (ii), a tendency toward an increased number of roots and root length in the plots with experimental warming (Figure 4). These results may be interpreted in the light of the continuous measurements of soil parameters (Figure $\mathbf{1}$ and Supplementary Figure S2) and their indirect effects on concentrations of soil nutrients.

Warming with OTCs has previously been observed to be an efficient method to increase the soil surface temperature. However, it may not yield the same effect in the deeper soil layers (Marion et al., 1997; Hobbie and Chapin, 1998; Sullivan and Welker, 2005; Natali et al., 2011). During summer time, the wetland in Blæsedalen is characterized by a horizontal water flow at the soil surface, which comes from a semi-permanent snowdrift to the East of the plots. This horizontal movement 
of water is considered to have partly transferred the heat away from the plots, preventing a significant effect of the OTCs on the soil temperature in depth. Hence, the observed root responses in plots with OTCs may be explained by indirect effects of increased temperature within the canopy. In plots exposed to experimental warming, the vegetation had a higher $\mathrm{C}$ assimilation, and it likely increased the allocation to the belowground biomass to tackle possible nutrient constraints. Consequently, the number of roots and root length increased to allow the exploitation of a larger volume of soil for nutrient uptake (Pregitzer et al., 2000; Arndal et al., 2014) and this was consistently observed over time, during each campaign (Table 4), and over the soil profile (Table 5). Similar observations were reported for a fen in Alaska, where a tendency in increased root biomass was linked to increased air temperature within the canopy and increased allocation belowground (Sullivan and Welker, 2005).

The maximum root number, total length and elongation were consistently observed across all treatments in the $0-20 \mathrm{~cm}$ depth interval, which is consistent with higher concentrations of plantavailable nutrients, as well as higher soil temperature in the upper soil layers as compared to freezing temperatures at the bottom of the active layer (Shaver and Billings, 1977).

The indirect positive effect of warming by OTCs on the number of roots and total root length over the soil profile further suggests an increased $\mathrm{C}$ allocation to roots in the deeper soil layers, as confirmed by the significant increase of maximum root growth in the $20-30 \mathrm{~cm}$ soil depth (Figure 6). A deeper rooting system allows the plant to take up nutrients released at the interface between active layer and permafrost. In previous studies, the root system of the sedge E. angustifolium has been observed to reach the top of the permafrost showing tolerance to the cold temperature (Shaver and Billings, 1977; Wang et al., 2016b, 2017). In the long-term, increased summer air temperature could further trigger a switch in the plant community composition of this wet tundra in favor of deeprooted sedges able to exploit the increased thickness of the active layer (Björk et al., 2007; Wookey et al., 2009).

Concerning the combination of winter snow accumulation and summer air warming, the cumulative observations along the soil profile and during the growing season suggest that the belowground biomass benefitted from the snow insulation during the cold period, which confirms our hypothesis iii. Furthermore, increased summer temperature may counterbalance the increase in snow depth, preventing a delay in the onset of the growing season. Based on our minirhizotrons observations, the combined effects on roots of snow addition and air warming were mainly driven by warming by OTCs for root number and root length and by snow addition for root diameter.

\section{Root Growth and Phenology}

The peak of root growth rates was observed between July 24th and August 13th (Figure 5). At the same site, Nielsen et al. (2017) measured at ambient conditions a peak in ambient gross ecosystem productivity (GEP) and ecosystem respiration (ER) on August 5th 2014. This indicates an overall match between the period of maximum aboveground activity and belowground production and a late season asynchrony as root growth continued until mid-September for all treatments after the occurrence of aboveground senescence, as assumed by the reduced rates of GEP (Nielsen et al., 2017). Similar seasonal root growth was reported in a recent study of Sloan et al. (2016) in which the authors observed synchronized maximum leaf and root production in a graminoid-dominated landscape in the subArctic region and a late season root growth after aboveground senescence. A prolonged belowground growth may be paired to $\mathrm{C}$ losses in the atmosphere through ER during the shoulder season (Blume-Werry et al., 2016), while instead the GEP is reduced or absent due to the senescence of the aboveground vegetation (Keenan et al., 2014; Toomey et al., 2015). This could cause an imbalance in the net C-flux between soil and atmosphere with the risk of increased C emissions; especially in ecosystems dominated by plant communities more sensitive to soil temperature rather than the length of the photoperiod. At the same time, a prolonged belowground growth may allow re-translocation and uptake of nutrients taking advantage of the maximum active layer depth and the still warm soil temperatures (Schimel et al., 2004; BlumeWerry et al., 2016).

The seasonal pattern of root growth corresponded to a significant increase of air temperature within the canopy with warming with OTCs. This is consistent with other studies carried out during the growing season 2014 at the same site, which measured a significant increase of ER (Nielsen et al., 2017) and GEP (Lindwall et al., 2016) under warming with OTCs. Yet, during the time of this study, it was not possible to witness significant seasonal changes in root growth rates across experimental treatments, but only a tendency between August and September (Figure 5). In spite of this, the temporal increase in the number of roots and their lengths corresponded with the patterns in root length growth under experimental warming. This can be explained as an indirect effect of the increased air temperature within the canopy on photosynthetic activity (Oechel and Billings, 1992; Shaver et al., 1992), which may have led to increased allocation belowground of photosynthate to sustain root growth, as also observed by other studies (Fitter et al., 1999; Tierney et al., 2003; Edwards et al., 2004). In contrast, Arndal et al. (2017), observed in a Danish mixed heathland grassland the opposite effect of experimental warming on root length in the upper $8-15 \mathrm{~cm}$ soil. However, in that study, a reduction in root length was simultaneously observed with a reduction of water availability, net photosynthesis and hence $\mathrm{C}$ allocation belowground.

\section{IMPLICATIONS AND CONCLUSION}

Our results suggest that in an Arctic ecosystem such as the one in Blæsedalen, short-term changes in air temperature and snow precipitation may lead to an increased allocation of $\mathrm{C}$ to the roots. However, most ecosystem C-models, which are used to predict net ecosystem responses to climate change in the Arctic, have not incorporated the sensitivity of tundra ecosystems to short-term changes in temperature regimes. Recent data from the Arctic showed dramatic changes in temperature regimes from year to year (Westergaard-Nielsen et al., 2018), hence it is critical 
to assess and take into account the short-term effects of plant responses to climate variability in order to look at the stability of ecosystem C-models. In Blæsedalen, the observed effects of snow accumulation on the relative production of roots as well as the patterns of root growth seemed to be triggered by changes in nutrient cycling during winter rather than by the shorter growing season, which contrasts with what we had originally hypothesized. We also conclude that multi-year measurements of single and combined effects of warming, snow and the associated changes in soil nutrient availability are needed to understand the full effects of increased winter and summer air temperature on root dynamics. Thus, by combining the knowledge of root biomass $\mathrm{C}$ responses to climate change with the recent improved understanding and mapping of greening of the Arctic (MyersSmith et al., 2015), we are close to see the hidden part of the iceberg, and thereby provide a more robust and improved measure of the total organic $\mathrm{C}$ balance of the Arctic. To assess this for longer terms requires that this type of measurements are continued in the years to come.

\section{AUTHOR CONTRIBUTIONS}

LD, MA, BE, and IS planned and designed the study. LD, MA, and $\mathrm{CN}$ collected the field data. LD analyzed the data and wrote the paper with contributions from all the authors.

\section{REFERENCES}

Abramoff, R. Z., and Finzi, A. C. (2015). Are above- and below-ground phenology in sync? New Phytol. 205, 1054-1061. doi: 10.1111/nph.13111

Arndal, M. F., Schmidt, I. K., Kongstad, J., Beier, C., and Michelsen, A. (2014). Root growth and $\mathrm{N}$ dynamics in response to multi-year experimental warming, summer drought and elevated $\mathrm{CO} 2$ in a mixed heathland-grass ecosystem. Funct. Plant Biol. 41, 1-10. doi: 10.1071/fp13117

Arndal, M. F., Tolver, A., Larsen, K. S., Beier, C., and Schmidt, I. K. (2017). Fine root growth and vertical distribution in response to elevated co2, warming and drought in a mixed heathland-grassland. Ecosystems 1-16, 15-30. doi: 10.1007/s10021-017-0131-2

Berendse, F., and Aerts, R. (1987). Nitrogen-use-efficiency: a biologically meaningful definition? Funct. Ecol. 1, 293-296.

Björk, R. G., Majdi, H., Klemedtsson, L., Lewis-Jonsson, L., and Molau, U. (2007). Long-term warming effects on root morphology, root mass distribution, and microbial activity in two dry tundra plant communities in northern Sweden. New Phytol. 176, 862-873. doi: 10.1111/j.1469-8137.2007.02231.x

Blume-Werry, G., Wilson, S. D., Kreyling, J., and Milbau, A. (2016). The hidden season: growing season is $50 \%$ longer below than above ground along an arctic elevation gradient. New Phytol. 209, 978-986. doi: 10.1111/nph.13655

Bragg, P. L., Govi, G., and Cannell, R. Q. (1983). A comparison of methods, including angled and vertical minirhizotrons, for studying root-growth and distribution in a spring oat crop. Plant and Soil 73, 435-440. doi: 10.1007/ bf02184322

Buckeridge, K. M., and Grogan, P. (2010). Deepened snow increases late thaw biogeochemical pulses in mesic low arctic tundra. Biogeochemistry 101, 105121. doi: 10.1007/s10533-010-9426-5

Christensen, J. H., Krishna Kumar, K., Aldrian, E., An, S.-I., Cavalcanti, I. F. A., de Castro, M., et al. (2013). "Climate phenomena and their relevance for future regional climate change," in Climate Change 2013: The Physical Science Basis. Contribution of Working Group I to the Fifth Assessment Report of the Intergovernmental Panel on Climate Change, eds T. F. Stocker, D. Qin, G. K. Plattner, M. Tignor, S. K. Allen, J. Boschung, et al. (Cambridge: Cambridge University Press), 1535.

\section{FUNDING}

This study was funded by The Danish National Research Foundation (CENPERM DNRF100) with additional funding provided by the EU-funded FP7 infrastructure INCREASE (Grant \#227628) and participating institutions.

\section{ACKNOWLEDGMENTS}

We wish to thank Jens Gammeltoft, Per Freiberg, and Paul Christiansen for helping with the preparation and installation of the minirhizotrons; Frida Lindwall, Nynne Marie Rand Ravn, and Kristine Dyrnum for their help in collecting root images in the field. We also wish to thank Jean-Baptiste Borres for helping with the image analysis software and Romain Baudet for assistance in the laboratory.

\section{SUPPLEMENTARY MATERIAL}

The Supplementary Material for this article can be found online at: https://www.frontiersin.org/articles/10.3389/fpls.2018.01258/ full\#supplementary-material

Cooper, E. J. (2014). Warmer shorter winters disrupt arctic terrestrial ecosystems. Annu. Rev. Ecol. Evol. Syst. 45, 271-295. doi: 10.1146/annurev-ecolsys-120213091620

Cooper, E. J., Dullinger, S., and Semenchuk, P. (2011). Late snowmelt delays plant development and results in lower reproductive success in the high arctic. Plant Sci. 180, 157-167. doi: 10.1016/j.plantsci.2010.09.005

Edwards, E. J., Benham, D. G., Marland, L. A., and Fitter, A. H. (2004). Root production is determined by radiation flux in a temperate grassland community. Glob. Chang. Biol. 10, 209-227. doi: 10.1111/j.1529-8817.2003. 00729.x

Elmendorf, S. C., Henry, G. H. R., Hollister, R. D., Björk, R. G., BoulangerLapointe, N., Cooper, E. J., et al. (2012). Plot-scale evidence of tundra vegetation change and links to recent summer warming. Nat. Clim. Chang. 2, 453-457. doi: $10.1038 /$ nclimate1465

Ernakovich, J. G., Hopping, K. A., Berdanier, A. B., Simpson, R. T., Kachergis, E. J., Steltzer, H., et al. (2014). Predicted responses of arctic and alpine ecosystems to altered seasonality under climate change. Glob. Chang. Biol. 20, 3256-3269. doi: $10.1111 /$ gcb. 12568

Fitter, A. H., Self, G. K., Brown, T. K., Bogie, D. S., Graves, J. D., Benham, D., et al. (1999). Root production and turnover in an upland grassland subjected to artificial soil warming respond to radiation flux and nutrients, not temperature. Oecologia 120, 575-581. doi: 10.1007/s004420050892

Giblin, A. E., Nadelhoffer, K. J., Shaver, G. R., Laundre, J. A., and McKerrow, A. J. (1991). Biogeochemical diversity along a riverside toposequence in arctic Alaska. Ecol. Monogr. 61, 415-435. doi: 10.2307/2937049

Gill, R. A., and Jackson, R. B. (2000). Global patterns of root turnover for terrestrial ecosystems. New Phytol. 147, 13-31. doi: 10.1046/j.1469-8137.2000.0 0681.x

Hansen, B. U., Elberling, B., Humlum, O., and Nielsen, N. (2006). Meteorological trends $(1991-2004)$ at arctic station, central west greenland $\left(69 \circ 15^{\prime} \mathrm{N}\right)$ in a 130 years perspective. Danish J. Geogr. 106, 45-55. doi: 10.1080/00167223.2006. 10649544

Hendrick, R. L., and Pregitzer, K. S. (1996). Applications of minirhizotrons to understand root function in forests and other natural ecosystems. Plant Soil 185, 293-304. doi: 10.1007/bf02257535 
Hill, G. B., and Henry, G. H. R. (2011). Responses of high arctic wet sedge tundra to climate warming since 1980. Glob. Chang. Biol. 17, 276-287. doi: 10.1111/j. 1365-2486.2010.02244.x

Hobbie, S. E., and Chapin, F. S. (1998). Response of tundra plant biomass, aboveground production, nitrogen, and $\mathrm{CO} 2$ flux to experimental warming. Ecology 79, 1526-1544.

Hollesen, J., Buchwal, A., Rachlewicz, G., Hansen, B. U., Hansen, M. O., Stecher, O., et al. (2015). Winter warming as an important co-driver for Betula nana growth in western Greenland during the past century. Glob. Chang. Biol. 21, 2410-2423. doi: $10.1111 /$ gcb.12913

Hugelius, G., Strauss, J., Zubrzycki, S., Harden, J. W., Schuur, E. A. G., Ping, C. L., et al. (2014). Estimated stocks of circumpolar permafrost carbon with quantified uncertainty ranges and identified data gaps. Biogeosciences 11, 6573-6593. doi: 10.5194/bg-11-6573-2014

Iversen, C. M., Ledford, J., and Norby, R. J. (2008). CO2 enrichment increases carbon and nitrogen input from fine roots in a deciduous forest. New Phytol. 179, 837-847. doi: 10.1111/j.1469-8137.2008.02516.x

Iversen, C. M., Murphy, M. T., Allen, M. F., Childs, J., Eissenstat, D. M., Lilleskov, E. A., et al. (2012). Advancing the use of minirhizotrons in wetlands. Plant Soil 352, 23-39. doi: 10.1007/s11104-011-0953-1

Iversen, C. M., Sloan, V. L., Sullivan, P. F., Euskirchen, E. S., McGuire, A. D., Norby, R. J., et al. (2015). The unseen iceberg: plant roots in arctic tundra. New Phytol. 205, 34-58. doi: 10.1111/nph.13003

Jonasson, S. (1988). Evaluation of the Point Intercept Method for the Estimation of Plant Biomass. Oikos 52, 101-106. doi: 10.2307/3565988

Jonasson, S., Michelsen, A., Schmidt, I. K., and Nielsen, E. V. (1999). Responses in microbes and plants to changed temperature, nutrient, and light regimes in the arctic. Ecology 80, 1828-1843. doi: 10.1890/0012-9658(1999)080[1828: RIMAPT]2.0.CO;2

Keenan, T. F., Darby, B., Felts, E., Sonnentag, O., Friedl, M. A., Hufkens, K., et al. (2014). Tracking forest phenology and seasonal physiology using digital repeat photography: a critical assessment. Ecol. Appl. 24, 1478-1489. doi: 10.1890/130652.1

Khorsand Rosa, R., Oberbauer, S. F., Starr, G., Parker La Puma, I., Pop, E., Ahlquist, L., et al. (2015). Plant phenological responses to a long-term experimental extension of growing season and soil warming in the tussock tundra of Alaska. Glob. Chang. Biol. 21, 4520-4532. doi: 10.1111/gcb.13040

Kong, D. L., Wang, J. J., Kardol, P., Wu, H. F., Zeng, H., Deng, X. B., et al. (2016). Economic strategies of plant absorptive roots vary with root diameter. Biogeosciences 13, 415-424. doi: 10.5194/bg-13-415-2016

Lauenroth, W. K., and Gill, R. (2003). "Turnover of root systems," in Root Ecology, eds H. de Kroon and E. J. W. Visser (New York, NY: Springer Berlin Heidelberg), 61-89. doi: 10.1007/978-3-662-09784-7_3

Leffler, A. J., and Welker, J. M. (2013). Long-term increases in snow pack elevate leaf $\mathrm{N}$ and photosynthesis in Salix arctica : responses to a snow fence experiment in the High Arctic of NW Greenland. Environ. Res. Lett. 8:025023. doi: 10.1088/ 1748-9326/8/2/025023

Lindwall, F., Svendsen, S. S., Nielsen, C. S., Michelsen, A., and Rinnan, R. (2016). Warming increases isoprene emissions from an arctic fen. Sci. Total Environ. 553, 297-304. doi: 10.1016/j.scitotenv.2016.02.111

Mack, M. C., Schuur, E. A. G., Bret-Harte, M. S., Shaver, G. R., and Chapin, F. S. (2004). Ecosystem carbon storage in arctic tundra reduced by long-term nutrient fertilization. Nature 431, 440-443. doi: 10.1038/nature02887

Marion, G. M., Henry, G. H. R., Freckman, D. W., Johnstone, J., Jones, G., Jones, M. H., et al. (1997). Open-top designs for manipulating field temperature in high-latitude ecosystems. Glob. Chang. Biol. 3, 20-32. doi: 10.1111/j.1365-2486. 1997.gcb136.x

McGuire, A. D., Christensen, T. R., Hayes, D., Heroult, A., Euskirchen, E., Kimball, J. S., et al. (2012). An assessment of the carbon balance of Arctic tundra: comparisons among observations, process models, and atmospheric inversions. Biogeosciences 9, 3185-3204. doi: 10.5194/bg-9-3185-2012

Mokany, K., Raison, R. J., and Prokushkin, A. S. (2006). Critical analysis of root: shoot ratios in terrestrial biomes. Glob. Chang. Biol. 12, 84-96. doi: 10.1111/j. 1365-2486.2005.001043.x

Mommer, L., Padilla, F. M., van Ruijven, J., de Caluwe, H., Smit-Tiekstra, A., Berendse, F., et al. (2015). Diversity effects on root length production and loss in an experimental grassland community. Funct. Ecol. 29, 1560-1568. doi: $10.1111 / 1365-2435.12466$
Morgner, E., Elberling, B., Strebel, D., and Cooper, E. J. (2010). The importance of winter in annual ecosystem respiration in the High Arctic: effects of snow depth in two vegetation types. Polar Res. 29, 58-74. doi: 10.1111/j.1751-8369. 2010.00151.x

Myers-Smith, I. H., Elmendorf, S. C., Beck, P. S. A., Wilmking, M., Hallinger, M., Blok, D., et al. (2015). Climate sensitivity of shrub growth across the tundra biome. Nat. Clim. Chang. 5, 887-891. doi: 10.1038/nclimate2697

Natali, S. M., Schuur, E. A. G., Trucco, C., Hicks Pries, C. E., Crummer, K. G., and Baron Lopez, A. F. (2011). Effects of experimental warming of air, soil and permafrost on carbon balance in Alaskan tundra. Glob. Chang. Biol. 17, 1394-1407. doi: 10.1111/j.1365-2486.2010.02303.x

Nielsen, C. S., Michelsen, A., Strobel, B. W., Wulff, K., Banyasz, I., and Elberling, B. (2017). Correlations between substrate availability, dissolved $\mathrm{CH} 4$, and $\mathrm{CH} 4$ emissions in an arctic wetland subject to warming and plant removal. J. Geophys. Res. Biogeosci. 122, 645-660. doi: 10.1002/2016jg0 03511

Oberbauer, S. F., Tweedie, C. E., Welker, J. M., Fahnestock, J. T., Henry, G. H. R., Webber, P. J., et al. (2007). Tundra CO2 fluxes in response to experimental warming across latitudinal and moisture gradients. Ecol. Monogr. 77, 221-238. doi: 10.1890/06-0649

Oechel, W. C., and Billings, W. D. (1992). "Effects of global change on the carbon balance of arctic plants and ecosystems," in Arctic Ecosystems in a Changing Climate: an Ecophysiological Perspective, eds F. S. III. Chapin, R. L. Jefferies, J. F. Reynolds, G. R. Shaver, J. Svoboda, and E. W. Chu (Cambridge, MA: Academic Press, Inc), 139-168. doi: 10.1016/B978-0-12-168250-7.50 $013-4$

Oliveira, M. G., van Noordwijk, M., Gaze, S. R., Brouwer, G., Bona, S., Mosca, G., et al. (2000). "Auger sampling, ingrowth cores and pinboard methods," in Root Methods. A Handbook, eds A. L. Smit, A. G. Bengough, C. Engels, M. van Noordwijk, S. Pelleris, and S. C. van de Gejin (New York, NY: Springer Berlin Heidelberg), 175-210.

Poorter, H., and Nagel, O. (2000). The role of biomass allocation in the growth response of plants to different levels of light. CO2, nutrients and water: a quantitative review. Aust. J. Plant Physiol. 27, 595-607. doi: 10.1071/pp99173

Pregitzer, K. S., King, J. A., Burton, A. J., and Brown, S. E. (2000). Responses of tree fine roots to temperature. New Phytol. 147, 105-115. doi: 10.1046/j.1469-8137. 2000.00689.x

Radville, L., McCormack, M. L., Post, E., and Eissenstat, D. M. (2016). Root phenology in a changing climate. J. Exp. Bot. 67, 3617-3628. doi: 10.1093/jxb/ erw062

SAS Institute Inc. (2013). The SAS System for Windows, Release 9.3. Cary, NC: SAS Institute Inc.

Schimel, J. P., Bilbrough, C., and Welker, J. A. (2004). Increased snow depth affects microbial activity and nitrogen mineralization in two Arctic tundra communities. Soil Biol. Biochem. 36, 217-227. doi: 10.1016/j.soilbio.2003.09.008

Schmidt, I. K., Jonasson, S., and Michelsen, A. (1999). Mineralization and microbial immobilization of $\mathrm{N}$ and $\mathrm{P}$ in arctic soils in relation to season, temperature and nutrient amendment. Appl. Soil Ecol. 11, 147-160. doi: 10.1016/s0929-1393(98) 00147-4

Schmidt, I. K., Jonasson, S., Shaver, G. R., Michelsen, A., and Nordin, A. (2002). Mineralization and distribution of nutrients in plants and microbes in four arctic ecosystems: responses to warming. Plant Soil 242, 93-106. doi: 10.1023/a: 1019642007929

Semenchuk, P. R., Elberling, B., Amtorp, C., Winkler, J., Rumpf, S., Michelsen, A., et al. (2015). Deeper snow alters soil nutrient availability and leaf nutrient status in high Arctic tundra. Biogeochemistry 124, 81-94. doi: 10.1007/s10533-0150082-7

Shaver, G. R., and Billings, W. D. (1977). Effects of daylength and temperature on root elongation in tundra-graminoids. Oecologia 28, 57-65. doi: 10.1007/ BF00346836

Shaver, G. R., Billings, W. D., Chapin, F. S., Giblin, A. E., Nadelhoffer, K. J., Oechel, W. C., et al. (1992). Global change and the carbon balance of arctic ecosystems. Bioscience 42, 433-441. doi: 10.2307/1311862

Sloan, V. L., Fletcher, B. J., and Phoenix, G. K. (2016). Contrasting synchrony in root and leaf phenology across multiple sub-Arctic plant communities. J. Ecol. 104, 239-248. doi: 10.1111/1365-2745.12506

Sturm, M., Schimel, J., Michaelson, G., Welker, J. M., Oberbauer, S. F., Liston, G. E., et al. (2005). Winter biological processes could help convert arctic tundra 
to shrubland. Bioscience 55, 17-26. doi: 10.1641/0006-3568(2005)055[0017: WBPCHC]2.0.CO;2

Sullivan, P. F., Arens, S. J. T., Chimner, R. A., and Welker, J. M. (2008). Temperature and microtopography interact to control carbon cycling in a high arctic fen. Ecosystems 11, 61-76. doi: 10.1007/s10021-007-9107-y

Sullivan, P. F., Sommerkorn, M., Rueth, H. M., Nadelhoffer, K. J., Shaver, G. R., and Welker, J. M. (2007). Climate and species affect fine root production with longterm fertilization in acidic tussock tundra near Toolik Lake. Alaska. Oecologia 153, 643-652. doi: 10.1007/s00442-007-0753-8

Sullivan, P. F., and Welker, J. M. (2005). Warming chambers stimulate early season growth of an arctic sedge: results of a minirhizotron field study. Oecologia 142, 616-626. doi: 10.1007/s00442-004-1764-3

Swindles, G. T., Morris, P. J., Mullan, D., Watson, E. J., Turner, T. E., Roland, T. P., et al. (2015). The long-term fate of permafrost peatlands under rapid climate warming. Sci. Rep. 5:17951. doi: 10.1038/srep17951

Tape, K., Sturm, M., and Racine, C. (2006). The evidence for shrub expansion in Northern Alaska and the Pan-Arctic. Glob. Chang. Biol. 12, 686-702. doi: 10.1111/j.1365-2486.2006.01128.x

Tierney, G. L., Fahey, T. J., Groffman, P. M., Hardy, J. P., Fitzhugh, R. D., Driscoll, C. T., et al. (2003). Environmental control of fine root dynamics in a northern hardwood forest. Glob. Chang. Biol. 9, 670-679. doi: 10.1046/j.1365-2486.2003. 00622.x

Toomey, M., Friedl, M. A., Frolking, S., Hufkens, K., Klosterman, S., Sonnentag, O., et al. (2015). Greenness indices from digital cameras predict the timing and seasonal dynamics of canopy-scale photosynthesis. Ecol. Appl. 25, 99-115. doi: 10.1890/14-0005.1

Van Der Krift, T. A. J., and Berendse, F. (2002). Root life spans of four grass species from habitats differing in nutrient availability. Funct. Ecol. 16, 198-203. doi: 10.1046/j.1365-2435.2002.00611.x

Walker, D. A., Gould, W. A., Maier, H. A., and Raynolds, M. K. (2002). The circumpolar arctic vegetation map: AVHRR-derived base maps, environmental controls, and integrated mapping procedures. Int. J. Remote Sens. 23, 45514570. doi: 10.1080/01431160110113854

Walker, D. A., Raynolds, M. K., Daniëls, F. J. A., Einarsson, E., Elvebakk, A., Gould, W. A., et al. (2005). The circumpolar arctic vegetation map. J. Veg. Sci. 16, 267-282. doi: 10.1111/j.1654-1103.2005.tb02365.x

Wang, P., Heijmans, M. M. P. D., Mommer, L., van Ruijven, J., Maximov, T. C., and Berendse, F. (2016a). Belowground plant biomass allocation in tundra ecosystems and its relationship with temperature. Environ. Res. Lett. 11:055003. doi: 10.1088/1748-9326/11/5/055003

Wang, P., Limpens, J., Mommer, L., van Ruijven, J., Nauta, A. L., Berendse, F., et al. (2017). Above- and below-ground responses of four tundra plant functional types to deep soil heating and surface soil fertilization. J. Ecol. 105, 947-957. doi: 10.1111/1365-2745.12718

Wang, P., Mommer, L., van Ruijven, J., Berendse, F., Maximov, T. C., and Heijmans, M. M. P. D. (2016b). Seasonal changes and vertical distribution of root standing biomass of graminoids and shrubs at a Siberian tundra site. Plant Soil 407, 55-65. doi: 10.1007/s11104-016-2858-5

Westergaard-Nielsen, A., Karami, M., Hansen, B. U., Westermann, S., and Elberling, B. (2018). Contrasting temperature trends across the ice-free part of Greenland. Sci. Rep. 8:1586. doi: 10.1038/s41598-018-19992-w

Wipf, S., and Rixen, C. (2010). A review of snow manipulation experiments in Arctic and alpine tundra ecosystems. Polar Res. 29, 95-109. doi: 10.1111/j.17518369.2010.00153.x

Wookey, P. A., Aerts, R., Bardgett, R. D., Baptist, F., Brathen, K. A., Cornelissen, J. H. C., et al. (2009). Ecosystem feedbacks and cascade processes: understanding their role in the responses of Arctic and alpine ecosystems to environmental change. Glob. Chang. Biol. 15, 1153-1172. doi: 10.1111/j.13652486.2008.01801.x

Zuur, A. F., Ieno, E. N., Walker, N. J., Saveliev, A. A., and Smith, G. M. (2009). "Mixed effects modelling for nested data," in Mixed Effects Models and Extensions in Ecology with R, eds M. Gail, K. Krickeberg, J. M. Samet, A. Tsiatis, and W. Wong (New York, NY: Springer-Verlag New York), 101-142. doi: 10.1007/978-0-387-87458-6_5

Conflict of Interest Statement: The authors declare that the research was conducted in the absence of any commercial or financial relationships that could be construed as a potential conflict of interest.

Copyright (C) 2018 D'Imperio, Arndal, Nielsen, Elberling and Schmidt. This is an open-access article distributed under the terms of the Creative Commons Attribution License (CC BY). The use, distribution or reproduction in other forums is permitted, provided the original author(s) and the copyright owner(s) are credited and that the original publication in this journal is cited, in accordance with accepted academic practice. No use, distribution or reproduction is permitted which does not comply with these terms. 